\title{
O gênero Megacyllene s. str. Casey (Coleoptera, Cerambycidae) na Mata Atlântica: descrição de duas espécies inéditas, chave para identificação e novas ocorrências
}

\author{
Allan Carelli Aragão ${ }^{1,2} \&$ Miguel A. Monné ${ }^{1,3}$
}

\begin{abstract}
'Museu Nacional, Universidade Federal do Rio de Janeiro, Quinta da Boa Vista, São Cristóvão, 20940-040 Rio de Janeiro-RJ, Brasil. monne@uol.com.br ${ }^{2}$ Universidade Federal do Estado do Rio de Janeiro, Avenida Pasteur 458, Urca, 20290-240 Rio de Janeiro-RJ, Brasil.. allancarelli@hotmail.com ${ }^{3}$ Pesquisador do CNPq.
\end{abstract}

\begin{abstract}
Megacyllene s. str. Casey (Coleoptera, Cerambycidae) in the Atlantic Rain Forest: description of two new species, identification key and new records. Twenty five species of Megacyllene (s. str.) Casey, 1912 ocurr in the Atlantic Rain Forest. New species described: M. globosa sp. nov. from Arapongas, Paraná, Brazil and M. guarani sp. nov. from San Estanislao, San Pedro, Paraguay. Megacyllene (Megacyllene) insignita (Perroud, 1855) is revalidated. A key to species of the Atlantic Rain Forest and new distributional records are added for 12 species.
\end{abstract}

KEYWORDS. Cerambycinae; Clytini; new taxa.

RESUMO. O gênero Megacyllene s. str. Casey (Coleoptera, Cerambycidae) na Mata Atlântica: descrição de duas espécies inéditas, chave para identificação e novas ocorrências. Na Mata Atlântica ocorrem vinte e cinco espécies de Megacyllene (s. str.) Casey, 1912. Espécies novas descritas: M. globosa sp. nov. de Arapongas, Paraná, Brasil e M. guarani sp. nov. de San Estanislao, San Pedro, Paraguai. Megacyllene (Megacyllene) insignita (Perroud, 1855) é revalidada. Chave para espécies da Mata Atlântica e novos registros de ocorrência para 12 espécies são fornecidos.

PALAVRAS-CHAVE. Cerambycinae; Clytini; novos táxons.

A tribo Clytini Mulsant, 1839 está representada na Região Neotropical por 21 gêneros e 247 espécies. Os gêneros Calloides LeConte, 1873, Clytopsis Casey, 1912, Clytus Laicharting, 1784, Euryscelis Dejean, 1835, Isotomus Mulsant, 1863 (uma espécie introduzida em Hispaniola) Plagionotus Mulsant, 1842 e Tylcus Casey, 1912 (cada um com uma espécie), Anthoboscus Chevrolat, 1860 (duas espécies), Dexithea Thomson, 1864 (três espécies), Ochraethes Chevrolat, 1860 (22 espécies), Placoclytus Chemsak \& Linsley, 1974 (três espécies), Placosternus Hopping, 1937 (quatro espécies), Tanyochraethes Chemsak \& Linsley, 1965 (oito espécies), Trichoxys Chevrolat, 1860 (15 espécies) e Xylotrechus Chevrolat, 1860 (sete espécies), distribuídos nas Antilhas, México e América Central. Chlorophorus Chevrolat, 1863 (uma espécies introduzida no Brasil), Cetimaju Galileo \& Martins, 2007 (uma espécie), Mecometopus Thomson, 1861 (49 espécies), Megacyllene Casey, 1912 (51 espécies, considerando as duas descritas no presente artigo), Mygalobas Chevrolat, 1862 (uma espécie) e Neoclytus Thomson, 1860 (75 espécies) com ampla distribuição do México a Argentina.

O objetivo é possibilitar a identificação das espécies que ocorrem na Mata Atlântica, com essa finalidade oferecemos chave de identificação e em cada espécie uma breve caracterização que auxilie no reconhecimento, sua distribuição, o material examinado e fotografia do habitus.

Concordamos com Di Iorio (1995) ao adotar como data de publicação de "Monographie du genre Clytus" o ano de 1836.
A obra foi escrita por Laporte \& Gory em 1835. Contudo o título do prefácio é: "Rapport fait a l'Academie Royale des Sciences, dans la seance du 4 Janvier 1836 pour un travail manuscrit intitulé: "Monographie du Genre Clytus.", além disso, consultando o original, constatamos que em cada uma das pranchas coloridas aparece "Publié par P. Duménil Paris 1836."

Em decorrência da publicação recente de um catálogo (Monné 2005), as citações em cada táxon se referem às descrições originais e à literatura posterior ao catálogo.

Abreviaturas utilizadas: DZUP, Coleção de Entomologia Pe. J. S. Moure, Departamento de Zoologia, Universidade Federal do Paraná, Curitiba, Paraná, Brasil; MNRJ, Museu Nacional, Universidade Federal do Rio de Janeiro, Rio de Janeiro, Brasil e MPEG, Museu Paraense "Emílio Goeldi”, Belém, Pará, Brasil.

\section{Megacyllene Casey, 1912}

Megacyllene Casey, 1912: 348, 351; Monné 2005: 85 (cat.). Espécie-tipo, Clytus antennatus White, 1855, por designação original. Cyllene Newman, 1840: 7 (non Gray 1834).

Espécie-tipo, Cyllene spinifera Newman, 1840, designação de Chevrolat 1860: 453.

Megacyllene foi descrito por Casey para Clytus antennatus White, 1855. Fisher (1945) propôs a substituição de Cyllene Newman, 1840 (non Cyllene Gray, 1834, Mollusca) por Megacyllene Casey, 1912. 
Divide-se em dois subgêneros: Megacyllene (s. str.) Casey, 1912 com 45 espécies na região neotropical, incluindo as duas descritas a seguir. No Brasil ocorrem 27 espécies, das quais 25 estão distribuídas na Mata Atlântica, considerando M. salhbergi (Aurivillius, 1913), descrita sem localidade precisa. As seis espécies de Megacyllene (Sierracyllene) Tippmann, 1960 estão restritas à região andina da Bolívia, Argentina e Chile.

A diagnose fornecida para M. sahlbergi foi baseada na descrição original e na figura por falta de exemplares nas coleções brasileiras.

Redescrição do gênero (adaptada de Linsley, 1964: 78). Cabeça com o rostro largo, ou mais largo que longo; terceiro antenômero de comprimento igual ao quarto, quinto ao décimo segmentos subserrados, terceiro a sexto com espinho interno no ápice. Pronoto lateralmente escavado na base; prosterno com o processo intercoxal vertical, não dilatado para trás; metasterno subvertical na frente, convexo após declive. Élitros gradualmente estreitados posteriormente; ápices emarginados ou obliquamente truncados, raramente espinhosos.

\section{Chave para as espécies de Megacyllene (s. str.) com ocorrência na Mata Atlântica}

1. Protórax com tubérculo lateral no início do terço posterior

1'. Protórax arredondado nos lados ou levemente anguloso no inicio do terço posterior

2(1). Pronoto coberto com densa pubescência acinzentada com três manchas castanho-escuras; élitros castanho-escuro com três faixas transversais de pubescência acinzentada (Fig. 1) ......... M. nebulosa (Laporte \& Gory)

2'. Pronoto com três faixas de pubescência amarelada; élitros castanho-avermelhados com cinco faixas transversais de pubescência amarela (Fig. 2) ............. M. guarani sp. nov.

3(1). Protórax e élitros sem faixas de pubescência ou apenas com pequenas máculas nos élitros

3'. Protórax e élitros com faixas de pubescência ou manchas desenvolvidas

4(3). Élitros castanho-avermelhados, com pequenas manchas amareladas esparsas; face ventral coberta com densa pubescência amarelo-esverdeada, exceto área glabra na parte central dos urosternitos (Fig. 3) ..... M. unicolor Fuchs

4'. Élitros pretos, sem faixas ou manchas de pubescência; metade posterior dos metepisternos e lateral do primeiro urosternito recobertos com pubescência amarelada (Fig. 4) ......................................... ebenina Napp \& Monné

5(3) Pronoto com pubescência uniforme, sem faixas de coloração diferente .....

5 '. Pronoto com faixas de pubescência de coloração diferente da pubescência predominante

6(5). Pronoto revestido com pubescência amarela (Fig. 5) .... M. lanei (Tippmann)

6'. Pronoto recoberto com pubescência preta..................... 7
7(6). Élitros com larga faixa mediana transversal de pubescência amarelo-acinzentada e duas grandes manchas circulares amarelo-douradas no terço distal (Fig. 6) ....... M. cleroides (Melzer)

7'. Élitros com três a quatro faixas transversais ou oblíquas de pubescência

8(7). Élitros com predominância de pubescência castanhoamarelada e quatro faixas estreitas amareladas, duas na metade anterior ascendentes da sutura para a margem, uma pós-mediana descendente e a última transversal anteapical; margem distal dos urosternitos com densa pubescência alaranjada (Fig. 7) .................... M.bonplandi (Gounelle)

8'. Élitros com predominância de pubescência preta ........ 9

9(8). Metade anterior dos élitros com três faixas moderadamente estreitas de pubescência acinzentada, as duas anteriores ascendentes da margem para a sutura, a terceira transversal e mancha amarelada larga anteapical; urosternito basal com mácula lateral de pubescência esbranquiçada (Fig. 8) ... M.hoffmanni (Laporte \& Gory)

9'. Metade anterior dos élitros com grande mancha cinzenta subarredondada látero-dorsal; manchas de pubescência amarelada apenas nos lados do primeiro urosternito (Fig. 9) M.mellyi (Chevrolat)

10(5). Pronoto com até duas faixas transversais ou manchas de pubescência bem definidas .................................. 11

10'. Pronoto com três ou mais faixas transversais de pubescência . 15

11(10). Pronoto com uma faixa transversal anterior e uma posterior de pubescência amarela (às vezes com vestígio de uma terceira faixa mediana) (Fig. 18)

M. insignita (Perroud)

11'. Pronoto sem faixas transversais ou, no máximo, com uma faixa de pubescência 12

12(11). Élitros com uma mancha látero-posterior de pubescência esbranquiçada; os dois urosternitos basais com mancha lateral de pubescência esbranquiçada. (Fig. 10) ............................................. chalybeata (White)

12'. Élitros com quatro faixas transversais de pubescência ...

13(12). Os três urosternitos anteriores com manchas laterais de pubescência amarelada. (Fig. 11)

M. latreillei (Laporte \& Gory)

13'. Apenas os dois urosternitos anteriores com manchas laterais de pubescência ............................................. 14

14(13). Élitros com todas as faixas esbranquiçadas; os dois urosternitos basais com manchas de pubescência, no primeiro amarela e no segundo branca

M. sahlbergi (Aurivillius)

14'. Élitros com a faixa basal de coloração amarelada, a mediana alaranjada e as demais variando entre alaranjado e amarelado; os dois urosternitos basais com manchas laterais de pubescência amarelada (Fig. 12) .... M. mellyi (Chevrolat) 
15(10). Pronoto com mais de três faixas de pubescência (frequentemente a terceira reduzida a duas manchas látero-posteriores) 16

15'. Pronoto com três faixas de pubescência.. 20

16(15). Os dois urosternitos basais com manchas laterais de pubescência, no primeiro amarela e no segundo branca (Fig. 13) M. falsa (Chevrolat)

16'. Urosternitos com outro padrão de manchas .. 17

17(16). Élitros com pelo menos duas faixas de pubescência de cor esbranquiçada, as restantes amarelas (Fig. 14) .... M. designata (Chevrolat)

17'. Élitros com quatro faixas de pubescência amarela (às vezes a quarta com mancha sutural esbranquiçada) ... 18

18(17). Pronoto com quatro faixas de pubescência (a terceira entre a central e a posterior reduzida a duas manchas na margem do ângulo posterior) (Fig. 15)

M. globosa sp. nov.

18'. Pronoto com cinco faixas de pubescência ..... 19

19(18). Protórax látero-posteriormente subgloboso; tegumento das pernas castanho-alaranjado com coloração diferente do resto do corpo (Fig. 16)

M. anacantha (Chevrolat)

19'. Protórax látero-posteriormente subanguloso; tegumento das pernas castanho-escuro a castanho-avermelhado com a mesma coloração do resto do corpo (Fig. 17) M acuta (Germar)

20(15). Élitros com menos de cinco faixas de pubescência ... 21

20'. Élitros com cinco faixas de pubescência .. 22

21(20). Élitros com quatro faixas transversais de pubescência amarelada (Fig. 18) M. insignita (Perroud)

21'. Élitros com três faixas de pubescência amarelada (Fig. 19) M. spixi (Laporte \& Gory)

22(20). Tegumento castanho-avermelhado; pronoto e élitros cobertos por curta e densa pubescência acastanhada, que mascara faixas e manchas (Fig. 20)

M. castanea (Laporte \& Gory)

22'. Tegumento de outra cor; pronoto e élitros com faixas e manchas contrastantes 23

23(22). Segunda faixa de pubescência dos élitros a partir da base dividida em manchas amarelas (Fig. 21)

M. proxima (Laporte \& Gory)

23'. Segunda faixa de pubescência dos élitros continua, esbranquiçada ou amarelada 24

24(25). Mesepisternos com pubescência amarela no terço basal 26

24'. Mesepisternos com pubescência amarela no quarto basal 25

25(24). Metepisternos com 2 manchas de pubescência: uma anterior menor e outra posterior maior; dimensões reduzidas, não mais de $10 \mathrm{~mm}$ de comprimento (Fig. 22) .......
M. minuta (Chevrolat)

25'. Metepisterno com pubescência densa disposta em mancha única (Fig. 23) M. patruelis (Chevrolat)

26(24). Élitros com faixas de pubescência amarelada, a basal reta, e as demais arqueadas; mancha sutural nas faixas arqueadas; mácula de pubescência amarela nos metepisternos, com frequência não dividida (Fig. 24) ....

M. congener (Laporte \& Gory)

26'. Élitros com todas as faixas de pubescência arqueadas, amareladas (às vezes a segunda branca), apenas as três últimas com manchas suturais; mancha de pubescência nos metepisternos frequentemente dividida (Fig. 25) ..... M. rufipes (Laporte \& Gory)

\section{Megacyllene (Megacyllene) nebulosa (Laporte \& Gory, 1836)}

(Fig. 1)

Clytus nebulosus Laporte \& Gory, 1836: 11, pr. 3, fig. 11.

Megacyllene nebulosa; Di Iorio 2006a: 9 (distr.); 2006b: 165 (distr., hosp.). Megacyllene (Megacyllene) nebulosa; Monné 2005: 92 (cat.); Di Iorio 2006a: 9.

Cyllene spinifera Newman, 1840: 8.

Tegumento castanho-escuro; protórax com tubérculo rombo lateral no início do terço posterior; pronoto com densa pubescência acinzentada e três manchas centro-longitudinais castanho-escuras. Élitros castanho-escuro com três faixas transversais de pubescência acinzentada. Os dois primeiros urosternitos com manchas laterais de pubescência esbranquiçada.

Distribuição geográfica: Brasil (Goiás, Mato Grosso, Paraná ao Rio Grande do Sul), Paraguai, Bolívia, Argentina e Uruguai.

Material examinado. ARGENTINA, Tucumán: macho, X.1934; Catamarca: Belén (Corral Quemado), macho, III.1934. La Rioja: Patquía, fêmea, XI.1959, M. Viana col. Córdoba: Córdoba, macho, 15.II.1989. Entre Rios: macho, 15.II.1920, macho, I.1941. Buenos Aires: macho, fêmea, J. Bosq col. La Pampa: macho, I.1930, macho, 1.III.1973, A. Mesa col. URUGUAI, Paysandú: Puerto Pepe Aji, fêmea, 16.XII.1966, C. S. Carbonell, P.R.San Martín e M. A. Monné col. Todos no MNRJ.

\section{Megacyllene (Megacyllene) guarani sp. nov.}

(Fig. 2)

Etimologia. O epíteto refere-se à notável e numerosa nação indígena da América do Sul, aparentada aos tupis, que dominou grande parte do Brasil, Paraguai, Argentina e Uruguai.

Macho. Tegumento castanho-avermelhado. Fronte com carena em forma de "Y" dividida pela sutura fronto-mediana que se estende até a parte posterior da cabeça; pelos longos esparsos na parte posterior da cabeça e nas genas; mandíbulas com pubescência amarelada na base; genas com densa pubescência amarelada que se estende pela região posterior do vértice numa faixa transversal. Antenas alcançam o terço 
basal dos élitros; escapo duas vezes mais longo que os antenômeros III ou IV; antenômeros III-VI com espinhos no lado interno do ápice; antenômeros III-X serreados no lado externo do ápice. Protórax subquadrado, com projeções laterais no terço posterior; pronoto com três faixas transversais de pubescência amarelada; pontuação fina e densa em toda superfície, parcialmente coberta por pubescência densa castanho-escura. Processo prosternal truncado posteriormente; processo mesosternal com forte declive anterior. Escutelo com margem posterior coberta por pubescência amarelada. Élitros com carena longitudinal aproximada da sutura na metade apical; com cinco faixas transversais de pubescência amarelada, a segunda e a terceira em forma de "V" invertido; a quarta transversal com mancha compacta na sutura e a quinta oblíqua, ascendente da margem para a sutura; ápices obliquamente emarginados; pontuação fina e esparsa, parcialmente coberta por densa pubescência castanho-avermelhada.

Face ventral com pubescência amarelada, exceto mancha de pubescência esbranquiçada nas metacoxas; mesepisterno com pubescência restrita à metade apical; metepisterno com pubescência dividida em duas manchas. Pernas castanhoavermelhadas, com pubescência esbranquiçada; pro e mesofêmures subclavados, os segundos em menor grau; metafêmures lineares; mesotarsômero I mais longo que duas vezes o II; metatarsômero I igual ou mais longo que todos os outros reunidos. Os quatro primeiros ventritos com duas manchas de pubescência laterais amareladas; último urotergito com mancha de pubescência amarelada e ápice levemente sinuoso; último ventrito com ápice arredondado.

Fêmea. Antenas alcançam o meio dos élitros. Último urotergito com ápice truncado; último urosternito com ápice levemente mais projetado que no macho.

Dimensões, em mm, macho/fêmea. Comprimento total, 24,0/25,0; comprimento do protórax, 5,0/5,0; maior largura do protórax, 6,0/6,2; comprimento dos élitros, 16,0/17,0; largura umeral, 6,6/7,4.

Material-tipo. Holótipo macho e parátipo fêmea, PARAGUAI, São Pedro: San Estanislao, I. 1946, J.M.Bosq col. (MNRJ).

Discussão. M.(M.) guarani sp. nov. é semelhante a M.(M) congener (Laporte \& Gory, 1836), mas difere na presença de pequenas projeções laterais no terço posterior do protórax, no aspecto levemente ondulado da primeira faixa de pubescência elitral e na pubescência do mesepisterno, restrita à metade distal. Em M. (M.) congener o terço posterior do protórax é apenas levemente anguloso; a primeira faixa de pubescência elitral é reta e a pubescência do mesepisterno atinge o terço basal.

\section{Megacyllene (Megacyllene) unicolor Fuchs, 1955}

(Fig. 3)

Megacyllene unicolor Fuchs, 1955: 49; Galileo \& Martins 2006: 90. (distr.). Megacyllene (Megacyllene) unicolor; Monné 2005: 94 (cat); Monné et al. 2009: 6 (distr); Monné et al. 2010: 239 (distr.).

Megacyllene lateripilosa Zajciw, 1963: 171.
Tegumento castanho-avermelhado. Protórax levemente anguloso no inicio do terço posterior; pronoto coberto com pubescência castanho-avermelhada sem faixas; Élitros castanho-avermelhados, revestidos com pubescência casta- nhoavermelhada e pequenas manchas dorsais de pubescência amarelada. Face ventral coberta com densa pubescência amarelo-esverdeada, exceto área glabra mediana nos urosternitos.

Distribuição geográfica: Brasil (Rio de Janeiro ao Rio Grande do Sul), Argentina (Misiones, Corrientes, Entre Ríos), Paraguai e Uruguai.

Material examinado. BRASIL, Minas Gerais: Poços de Caldas, macho, 23.X.1964, O. Roppa \& O. Leoncini col. Rio de Janeiro: Rio de Janeiro (Represa Rio Grande), fêmea, X.1971, F. M. Oliveira col. Santa Catarina: Águas Mornas (Teresópolis), macho, sem data, Fruhstorfer col.; Corupá, 3 machos, XI.1949, A. Maller col. (holótipo e parátipos de Megacyllene lateripilosa Zajciw, 1963); (Rio Vermelho), fêmea, A. Maller col. (parátipo de M. lateripilosa), XII.1943, A.Maller col.; mesma localidade e coletor, 2 machos, XII.1956; macho, X.1972, fêmea, XI.1972; Mafra, fêmea XII.1937, A. Maller col.; Rio Natal, fêmea, XII.1964, A. Maller col. Seara (Nova Teutonia), macho, XI.1956, F.Plaumann col. Rio Grande do Sul: Pelotas, fêmea, 7.XII.1966, C. M. Biezanko col. PARAGUAI, Guairá: Villarica, fêmea, XI.1941. ARGENTINA, Misiones: San Pedro, 2 machos, I.1956, M. J. Viana col. URUGUAI, Lavalleja: Cantera Sarralde, fêmea, 21.XII.1958, M. A. Monné col. Montevideo: Montevideo, macho, L. Barattini col. Todos no MNRJ.

\section{Megacyllene (Megacyllene) ebenina Monné \& Napp, 2004}

(Fig. 4)

Megacyllene (Megacyllene) ebenina Monné \& Napp, 2004: 323; Monné 2005: 89 (cat.).

Tegumento preto. Protórax levemente anguloso no inicio do terço posterior; pronoto sem faixas de pubescência. Élitros pretos, sem faixas de pubescência. Urosternito basal com mancha lateral de pubescência amarela.

Distribuição geográfica: Brasil (Santa Catarina).

Material examinado. BRASIL, Santa Catarina: Corupá (Rio Vermelho), macho, (holótipo), XII. 1956, A. Maller col. (MNRJ).

\section{Megacyllene (Megacyllene) lanei (Tippmann, 1953)}

(Fig. 5)

Cyllene lanei Tippmann, 1953: 218.

Megacyllene (Megacyllene) lanei; Monné 2005: 90 (cat.).

Tegumento castanho-avermelhado. Protórax arredondado nos lados; pronoto coberto com densa pubescência amarela. Élitros com quatro faixas transversais onduladas de pubescência amarelada. Os três primeiros urosternitos com máculas laterais de pubescência amarelada.

Distribuição geográfica: Brasil (São Paulo ao Rio Grande do Sul).

Material examinado. BRASIL, Paraná: Curitiba, fêmea, XI.1944, R.Hots col. (MNRJ); macho, XI.1939, H. Zellibor col. (MNRJ). 

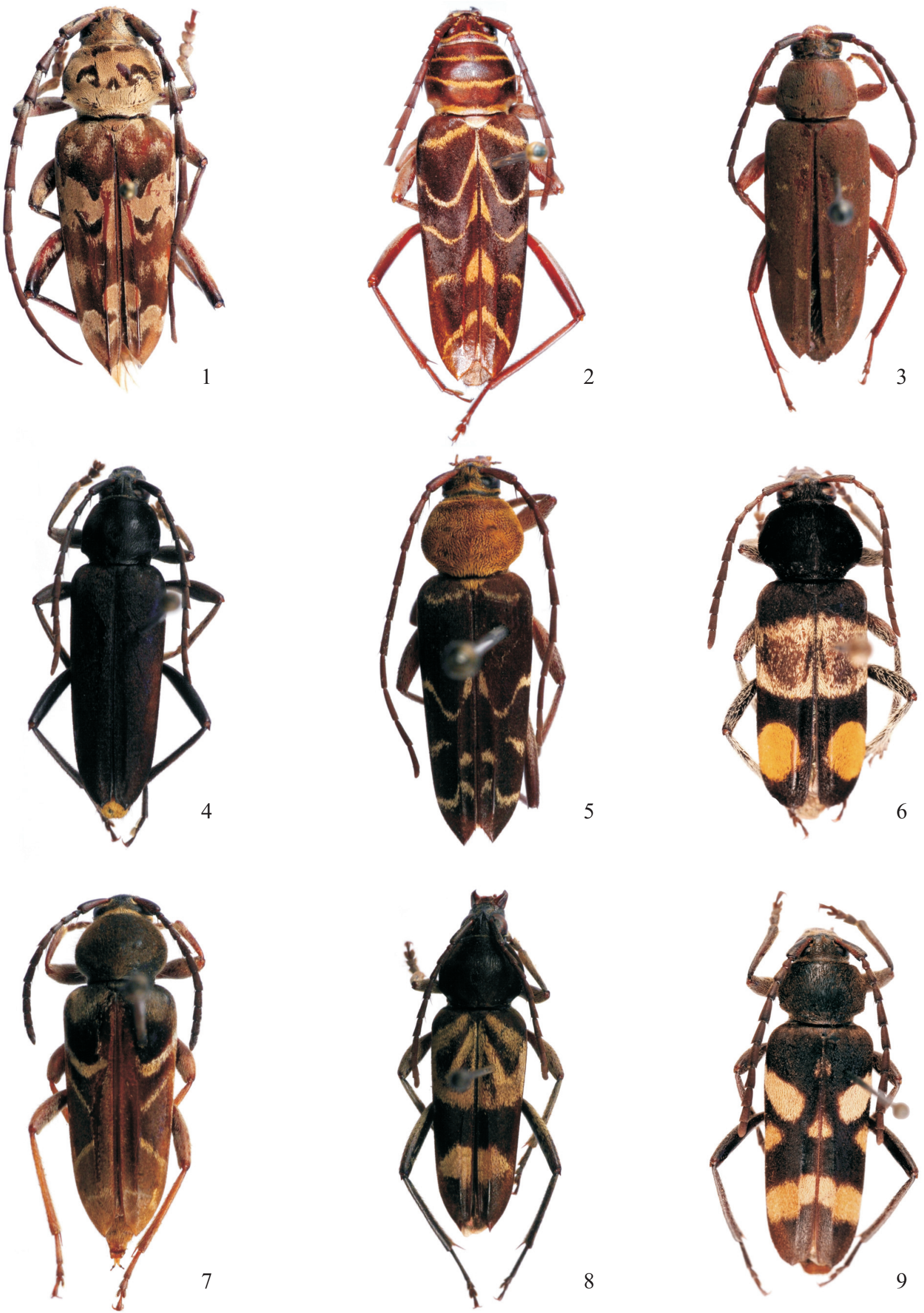

Figs. 1-9. 1, Megacyllene (Megacyllene) nebulosa; 2, M. (M.) guarani sp. nov.; 3, M. (M.) unicolor; 4, M. (M.) ebenina; 5, M. (M.) lanei; 6, M. (M.) cleroides; 7, M. (M.) bonplandi; 8, M. (M.) hoffmanni; 9, M. (M.) mellyi. 


\section{Megacyllene (Megacyllene) cleroides (Melzer, 1931)}

(Fig. 6)

Cyllene cleroides Melzer, 1931: 194

Megacyllene (Megacyllene) cleroides; Monné 2005: 89 (cat.).

Tegumento preto. Protórax arredondado nos lados; pronoto uniformemente coberto com pubescência preta. Élitros com uma larga faixa mediana transversal de pubescência amareloacinzentada e duas grandes manchas circulares amarelo- douradas no terço distal. Os dois primeiros urosternitos com máculas laterais de pubescência esbranquiçada.

Distribuição geográfica: Brasil (São Paulo, Paraná). Amplia-se a distribuição para Espírito Santo.

Material examinado. BRASIL, Espírito Santo: Baixo Guandu, fêmea, 20.VII.1970, C. Elias col. (DZUP).

\section{Megacyllene (Megacyllene) bonplandi (Gounelle, 1911)}

(Fig. 7)

\section{Cyllene bonplandi Gounelle, 1911: 83}

Megacyllene (Megacyllene) bonplandi; Monné 2005: 8 (cat.); Monné et al. 2009: 6 (distr); Monné et al. 2010: 239 (distr.).

Tegumento castanho. Protórax arredondado nos lados; pronoto uniformemente coberto com pubescência pretoacastanhada. Élitros com predominância de pubescência castanho-amarelada e quatro faixas oblíquas amarelas. Urosternitos com densa pubescência de coloração alaranjada na margem distal.

Distribuição geográfica: Brasil (Minas Gerais, Rio de Janeiro) e Argentina (Misiones). Amplia-se a distribuição no Brasil para Paraná e Santa Catarina.

Material examinado. BRASIL, Paraná: Curitiba, fêmea, 30.X.1935, Claretiano col.; (Mato Grego), fêmea, VII.1938, Claretiano col., mesma localidade e coletor, macho, 26.X.1935. Santa Catarina: Mafra, macho, fêmea, XII.1939, A. Maller col.; Rio Natal, macho, XI.1956, A. Maller col. ARGENTINA, Misiones: Loreto, macho, IX.1954. Todos no MNRJ.

\section{Megacyllene (Megacyllene) hoffmanni (Laporte \& Gory, 1836)}

(Fig. 8)

Clytus hoffmanni Laporte \& Gory, 1836: 13, pr. 3, fig. 13 bis.

Megacyllene (Megacyllene) hoffmanni; Monné 2005: 90 (cat.); Di Iorio 2006a: 5 .

Tegumento preto. Protórax arredondado nos lados; pronoto uniformemente coberto com pubescência preta. Metade anterior dos élitros com três faixas de pubescência acinzentada, as duas do terço anterior oblíquas, ascendentes da margem para a sutura a terceira mediana e transversal. Metade posterior com grande mácula cinzento-amarelada ante-apical. Urosternitos com manchas laterais de pubescência amarela.
Distribuição geográfica: Brasil (Paraná ao Rio Grande do Sul) e Paraguai. Amplia-se a distribuição no Brasil para São Paulo.

Material examinado. BRASIL, São Paulo: Teodoro Sampaio, macho, VIII.1986, F. M. Oliveira col. Paraná: Rolândia, macho, fêmea, VI.1941, A. Maller col.; macho, 8.X.1945, H. Zellibor col. Santa Mariana, fêmea, 7.XI.1949, H. Zellibor col. fêmea, 4.XI.1951, H. Zellibor col. PARAGUAI, Caaguazú: Caaguazú, macho, I.1949. Todos no MNRJ.

\section{Megacyllene (Megacyllene) mellyi (Chevrolat, 1862)}

(Figs. 9, 12)

Cyllene mellyi Chevrolat, 1862a: 54.

Megacyllene (Megacyllene) mellyi; Monné 2005: 91 (cat.); Monné et al. 2009: 6 (distr); Monné et al. 2010: 239 (distr.).

Megacyllene (Sierracyllene) mellyi; Di Iorio 2006a: 8 (distr.).

Tegumento preto Protórax arredondado nos lados; pronoto uniformemente coberto com pubescência preta, sem faixas de pubescência clara ou com apenas uma na margem posterior, cinzento-esbranquiçada; quando sem faixas de pubescência os élitros apresentam, na metade anterior, uma grande mancha subarredondada látero-dorsal cinzenta e manchas de pubescência amarelada apenas nos lados do primeiro urosternito (exemplares da Bolívia, fig. 9); quando apresentam a faixa posterior no pronoto os élitros possuem faixa basal amarelada, a mediana alaranjada e as restantes variam entre alaranjadas e amareladas e os lados dos dois primeiros urosternitos com máculas amareladas.

Distribuição geográfica: Brasil (Minas Gerais ao Rio Grande do Sul), Bolívia (Cochabamba, Santa Cruz), Paraguai, Argentina (Salta a Buenos Aires) e Uruguai.

Material examinado. BRASIL, Rio de Janeiro: Itatiaia, fêmea, 20.XI.1930, H. Zellibor col., (700m) macho, fêmea, 12.XI.1924, J. F. Zikán col. Paraná: Curitiba, fêmea, II.1964. Santa Catarina: Nova Teutônia, fêmea, 30.II.1934, F. Plaumann col.; mesma localidade e coletor, macho, I.1956, macho, 19.II.1965; Pinhal, macho, II.1952, A. Maller col.; São Bento do Sul, fêmea, XII.1972; fêmea, II.1976. Rio Grande do Sul: Porto Alegre, macho, 3.IV.1962; Santo Augusto, fêmea, X.1966, O. Roppa col. BOLÍVIA, Cochabamba: fêmea, 7.XI.1946, H. Zellibor col.; (2000 m \}, fêmea, III.1957. Todos no MNRJ.

\section{Megacyllene (Megacyllene) chalybeata (White, 1855)}

(Fig. 10)

Clytus chalybeatus White, 1855: 250.

Megacyllene (Megacyllene) chalybeata; Monné 2005: 89 (cat.).

Tegumento preto. Protórax levemente anguloso no início do terço posterior, onde o pronoto apresenta duas manchas circulares de pubescência amarela látero-dorsais. Élitros com três faixas oblíquas de pubescência esbranquiçada na metade anterior. Os dois primeiros urosternitos com máculas laterais de pubescência esbranquiçada. 

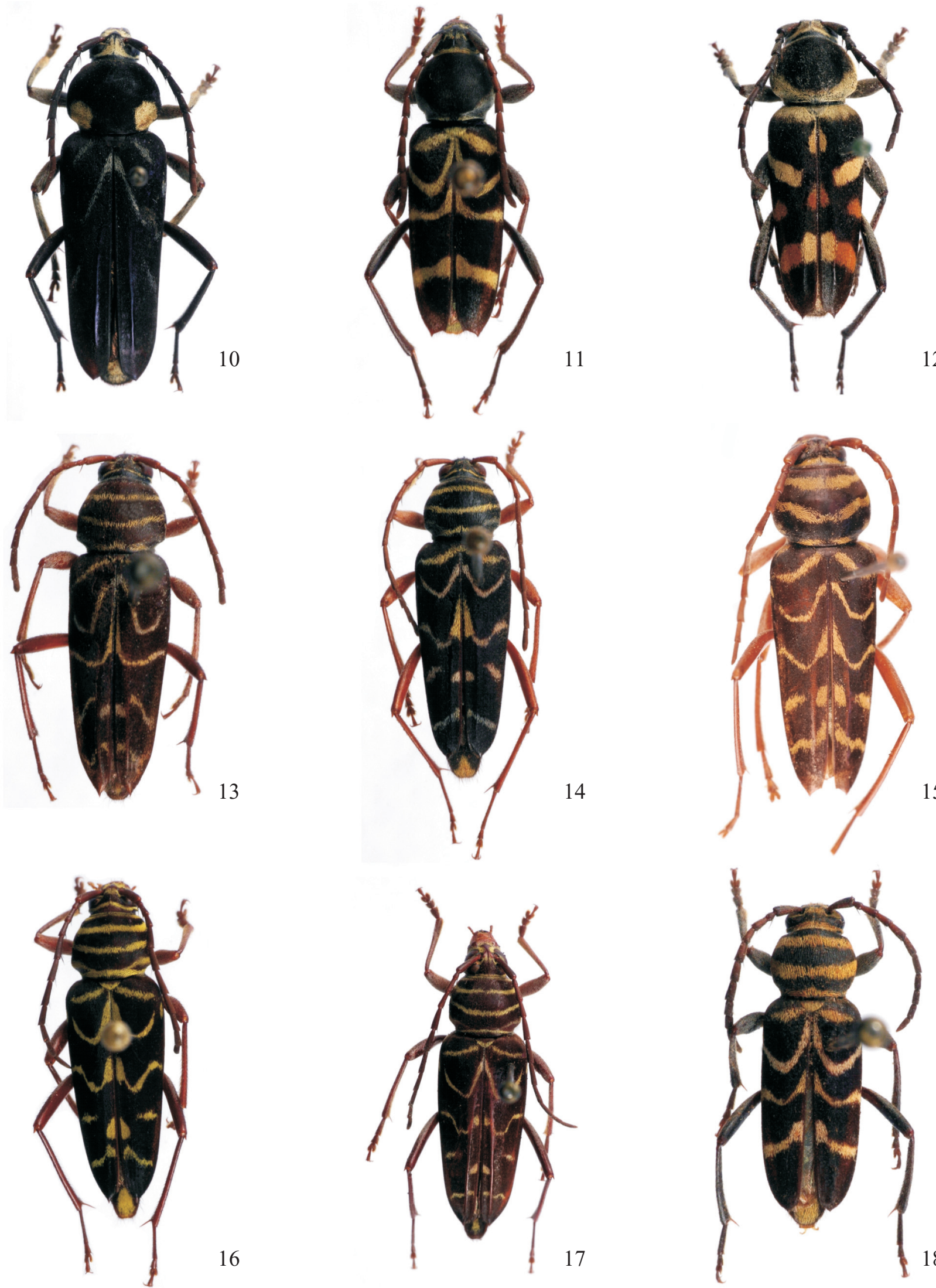

Figs. 10-18. 10, Megacyllene (Megacyllene) chalybeata; 11, M. (M.) latreillei;12, M. (M.) mellyi;13, M. (M.) falsa;14, M. (M.) designata; 15, M. (M.) globosa sp. nov.; 16, M. (M.) anacantha; 17, M. (M.) acuta; 18, M. (M.) insignita. 
Distribuição geográfica: Guiana Francesa e Brasil (Espírito Santo). Amplia-se a distribuição no Brasil para Pará, São Paulo e Santa Catarina.

Material examinado. BRASIL, Pará: Xingú, fêmea, 14.I.2008, P. Sá col. (MPEG). São Paulo: São Paulo (Cantareira), macho, 19.XI.1939, Dr. Nick col. (MNRJ); (Jabaquara), 2 machos, 7.XI.1939, H.Zellibor-Hauf col. (MNRJ); Peruíbe, fêmea, 7.XII.1945, H.Zellibor col. (MNRJ). Santa Catarina: Rio Natal, (400 m), fêmea, XII.1964 (MNRJ).

\section{Megacyllene (Megacyllene) latreillei (Laporte \& Gory, 1836)}

(Fig. 11)

Clytus latreillei Laporte \& Gory, 1836: 91, pr. 17, fig. 106

Megacyllene (Megacyllene) latreillei; Monné, 2005: 90 (cat.); Di Iorio 2006a: 7 (in syn. com insignita).

Cyllene unicoloricollis Fuchs, 1961: 447.

Tegumento preto. Protórax arredondado nos lados; pronoto com uma faixa posterior esbranquiçada. Élitros com quatro faixas transversais de pubescência amarela. Manchas de pubescência amarelada nos lados dos três primeiros urosternitos.

Distribuição geográfica: Brasil (Rio Grande do Sul), Argentina (Misiones, Entre Ríos) e Uruguai. Amplia-se a distribuição no Brasil para Minas Gerais, São Paulo, Paraná e Santa Catarina.

Material examinado. BRASIL, Minas Gerais: Maria da Fé, fêmea, XI.1980, G. Andrade col. São Paulo: Campos do Jordão, macho, 10.II.1952, H. Zellibor col., mesma localidade e coletor, fêmea, 21.II.1952, H. Zellibor col., mesma localidade fêmea, 19.II.1956, Ebenezer col.; Pinhal, macho, XII.1952, H. Zellibor col.; São José Barreiro (Serra da Bocaina, 1650 m), macho, XI.1969, Seabra \& Oliveira col.; mesma localidade (1680 m), fêmea, II.1972, P. S. Motta col. Paraná: Curitiba, fêmea, 30.X.1935, Claretiano col., mesma localidade, macho, 2 fêmeas, 17.I.1938, H. Zellibor col., macho, 2 fêmeas, I.1940, Claretiano col.; Ponta Grossa, fêmea, IX.1946, J. Junior col. Santa Catarina: Mafra, macho, XII.1938, A. Maller col. (800 m), fêmea, II.1964. Rio Grande do Sul: Santo Augusto, macho, XI.1968, O. Roppa col., macho, XII.1970, O.Roppa col. Todos no MNRJ.

\section{Megacyllene (Megacyllene) sahlbergi (Aurivillius, 1913)}

Cyllene sahlbergi Aurivillius, 1913: 237, fig. 58.

Megacyllene (Megacyllene) sahlbergi; Monné 2005: 93 (cat.).

Tegumento preto. Protórax levemente anguloso no início do terço posterior; pronoto com uma faixa transversal de pubescência interrompida na metade. Élitros com quatro faixas de pubescência esbranquiçada. Os dois urosternitos basais com manchas laterais de pubescência, no primeiro amarela e no segundo branca.

Distribuição geográfica: Descrita do Brasil sem localidade precisa.

\section{Megacyllene (Megacyllene) falsa (Chevrolat, 1862)}

(Fig. 13)

Cyllene falsa Chevrolat, 1862a: 51.

Megacyllene falsa; Di Iorio 2006b: 165 (distr., hosp.).

Megacyllene (Megacyllene) falsa; Monné 2005: 89 (cat.); Di Iorio 2006a:

5 (distr.); Monné et al. 2009: 6 (distr); Monné et al. 2010: 239 (distr.).

Tegumento preto. Protórax levemente anguloso no inicio do terço posterior; pronoto com três ou quatro faixas transversais de pubescência amarela. Élitros com cinco faixas transversais de pubescência amarela, a segunda e terceira a partir da base onduladas, a primeira e quarta transversais, e a quinta levemente ascendente da margem para a sutura. Os dois urosternitos basais com mácula lateral de pubescência, no primeiro amarela e no segundo branca.

Distribuição geográfica: Brasil (Goiás, Bahia ao Rio Grande do Sul), Argentina (Formosa, Misiones, Entre Ríos), Paraguai e Uruguai.

Material examinado. BRASIL, Minas Gerais: Poços de Caldas (Morro do Ferro), fêmea, 1.XI.1970, Becker col. São Paulo: São Paulo (Jabaquara), fêmea, IV.1974, S.A.Fragoso col. Espírito Santo: Linhares, macho, III.1953, P. A. Teles col., mesma localidade e coletor, macho, V.1953, mesma localidade, macho, XII.1964, B.Silva col., fêmea, X.1966. Rio de Janeiro: Rio de Janeiro (Tijuca, Alto da Boa Vista), macho, V.1950, C. A. C. Seabra col.; (Corcovado), fêmea, 22.IX.1959, D. Zajciw col., mesma localidade, macho, III.1961, Alvarenga e Seabra col., macho, 30.XI.1966, Alvarenga e Seabra col.; Parque Nacional do Itatiaia, (700 m), macho, 30.I.1966, P. R. San Martín e M. A. Monné col. Paraná: Curitiba (Mato Grego), macho, 8.XII.1936, Claretiano col.; Rolândia, fêmea, XI.1951, A Maller col. Santa Catarina: Joinville, macho, III.1969; Pinhal, fêmea, XII.1953, A. Maller col. Rio Grande do Sul: Santo Augusto, fêmea, X.1966, O.Roppa col. Todos no MNRJ.

\section{Megacyllene (Megacyllene) designata (Chevrolat, 1862)}

(Fig. 14)

Cyllene designata Chevrolat, 1862a: 50.

Megacyllene (Megacyllene) designata; Monné 2005: 89 (cat.); Monné et al. 2010: 239 (distr.).

Tegumento preto. Protórax arredondado nos lados; pronoto com cinco faixas transversais de pubescência amarela. Élitros com cinco faixas onduladas de pubescência, que variam entre esbranquiçadas e amareladas, a terceira faixa a partir da base prolonga-se, na sutura em mancha sagitiforme. Com manchas de pubescência amarela nos lados dos três primeiros urosternitos.

Distribuição geográfica: Brasil (Rio de Janeiro, São Paulo). Amplia-se a distribuição para Minas Gerais e Paraná.

Material examinado. BRASIL, Minas Gerais: Passos, fêmea, 1217.XI.1962, C. Elias col. São Paulo: São Paulo (Cantareira), macho, 17.XII.1939, H. Zellibor col., 2 machos, X.1940, H. Zellibor col. (Parque do Estado), macho, 30.XI.1937, H. Zellibor col.; São José Barreiro (Serra da Bocaina, 1600 m), fêmea, XI.1967, Alvarenga e Seabra col. Rio de Ja- 
neiro: Petrópolis, macho, XII.1992, P. R. Magno col.; Teresópolis, 2 machos, 23-25.I.1957, D. Zajciw col., macho, 25.X.1960, D. Zajciw col. Paraná: 3 machos, fêmea, III.1937, V. Stawiarsky col.; Santa Mariana, fêmea, 1.XI.1944, H..Zellibor col. Todos no MNRJ.

\section{Megacyllene (Megacyllene) globosa sp. nov.} (Fig. 15)

Etimologia. Epíteto de origem latina referente ao formato globoso do protórax.

Tegumento castanho-avermelhado. Fronte com carena em forma de "Y" dividida pela sutura fronto-mediana que se estende até a parte posterior da cabeça; pelos longos esparsos espalhados na parte posterior da cabeça; pubescência amarelada ao redor dos olhos, estendendo-se para trás formando uma faixa transversal. Escapo 1,5 vezes mais longo que os antenômeros III ou IV; antenômeros III ao X serreados no lado interno do ápice.

Protórax globoso, com lados arredondados; pronoto com três faixas curvas de pubescência e duas manchas na margem posterior amareladas; com pontuação fina parcialmente coberta por esparsa pubescência curta, castanho-escura. Processo prosternal truncado posteriormente; processo mesosternal em forte declive anterior. Escutelo com curta pubescência esbranquiçada. Élitros com carenas longitudinais aproximadas da sutura na metade apical; com duas manchas umerais e cinco faixas transversais de pubescência amarelada: I a III recurvas, a terceira com mancha sagitiforme na sutura; ápices chanfrados, ângulo sutural com curto espinho; pontuação fina e densa, coberta por densa pubescência castanho-avermelhada. Último urotergito com mancha de pubescência amarelada.

Face ventral com pubescência amarelada; mesepisterno totalmente pubescente; metepisterno com pubescência dividida em duas manchas. Os três urosternitos basais com máculas laterais. Pernas castanho-avermelhadas, revestidas de pubescência esbranquiçada; pro- e mesofêmures subclavados; metafêmures lineares; meso e metatarsos com tarsômero I maior que duas vezes o II.

Dimensões, mm: Holótipo macho. Comprimento total, 16,5; comprimento do protórax, 3,7; largura do protórax, 3,0 na margem anterior e 4,0 na margem posterior, largura máxima no meio, 4,3; comprimento dos élitros, 11,2; largura umeral, 4,7 .

Material-tipo. Holótipo macho, BRASIL, Paraná: Arapongas, XI. 1951, A. Maller col. (MNRJ).

Discussão. $M$. (M.) globosa sp. nov. é semelhante a $M$. (M.) anacantha (Chevrolat, 1862), mas difere na coloração do tegumento, no número de faixas de pubescência do pronoto e na quarta faixa de pubescência elitral. Em $M$. (M.) anacantha $\mathrm{o}$ tegumento é preto, as faixas do pronoto são em número de cinco e na quarta faixa de pubescência dos élitros a mancha entre a carena e a margem situa-se anteriormente à mancha entre a sutura e a carena. Em M. (M.) globosa sp. nov. o tegumento é castanho-avermelhado, o pronoto tem três faixas de pubescência e na quarta faixa de pubescência dos élitros a mancha entre a carena e a margem encontra-se no mesmo nível que aquela entre a sutura e a carena.

\section{Megacyllene (Megacyllene) anacantha (Chevrolat, 1862)}

(Fig. 16)

Cyllene anacantha Chevrolat, 1862a: 52.

Megacyllene (Megacyllene) anacantha; Monné 2005: 86 (cat.); Monné et al. 2010: 239 (distr.).

Tegumento preto. Protórax subanguloso no início do terço posterior; pronoto com cinco faixas transversais de pubescência amarelada. Élitros com cinco faixas transversais de pubescência amarelada, as faixas terceira e quarta com mancha sagitiforme na sutura. Os quatro primeiros urosternitos com manchas laterais de pubescência amarela.

Distribuição geográfica: Brasil (Rio de Janeiro ao Rio Grande do Sul) e Argentina (Salta).

Material examinado. BRASIL, Pernambuco: $16 \mathrm{Km}$ oeste de Arcoverde, fêmea, V.1991, C. S. Carbonell col. Mato Grosso: Juína, fêmea, V.1986, B. Silva col. São Paulo: macho, 1983. Amparo, fêmea. Barueri, macho, 7.II.1955, K Lenko col. Paraná: Ortigueira, macho, XI.1945, J. Júnior col. ARGENTINA, Salta: Carapari, macho, 29.I.1945, Bridarolli col. Tucumán: San Pedro de Colalao, fêmea, II.1949, Arnau col. Misiones: Loreto, macho, A. A. Oglobin col. Corrientes: Parque Nacional Mburucuya, macho, 9.I.2008, Barbosa col. (MNRJ).

\section{Megacyllene (Megacyllene) acuta (Germar, 1821)}

(Fig. 17)

Clytus acutus Germar, 1821: 170

Megacyllene acuta; Di Iorio 2006b: 165 (distr., hosp.).

Megacyllene (Megacyllene) acuta; Monné 2005: 85 (cat.); Di Iorio 2006a: 2 (distr.); Monné et al. 2009: 6 (distr); Monné et al. 2010: 239 (distr.). Cyllene consimilis Chevrolat, 1862a: 52.

Cyllene exsanguis Chevrolat, 1862b: 527.

Tegumento preto. Protórax subanguloso no início do terço posterior; pronoto com cinco faixas transversais de pubescência amarelada. Élitros com cinco faixas transversais de pubescência amarelada, às vezes com uma das faixas ou manchas esbranquiçadas, variando entre os indivíduos na posição. Primeiros três ou quatro urosternitos com mancha de pubescência amarela.

Distribuição geográfica: Brasil (Goiás, Bahia ao Rio Grande do Sul), Bolívia (Santa Cruz), Paraguai, Argentina (Salta a Buenos Aires) e Uruguai.

Material examinado. BRASIL, Goiás: Serranópolis, macho, XI.1972, F M. Oliveira col. Minas Gerais: Passos, fêmea, XI.1961, C Elias col. São Paulo: Campos do Jordão, fêmea, 8.II.1956, Ebenezer col.; Teodoro Sampaio, macho, XI.1973, F.M. Oliveira col. Espírito Santo: Linhares, macho, X.1967, F. M. Oliveira col., fêmea, XI.1967, F.M. Oliveira col..macho, XI.1971, F. M. Oliveira col. Rio de Janeiro: Rio de Janeiro (Represa Rio Grande), macho, 1-15.IX.1960, F. M. Oliveira col. Paraná: Rolândia, macho, X.1949, A. Maller col. Santa Catarina: Corupá, fêmea, I.1958. Rio Grande do Sul: Santo Augusto, 2 machos, XI.1958, O. Roppa col., macho, fêmea, IV.1966, O. Roppa col., fêmea, X.1966, O. Roppa col. Todos no MNRJ. 


\section{Megacyllene (Megacyllene) insignita (Perroud, 1855) revalidada}

(Fig. 18)

Clytus insignitus Perroud, 1855: 388.

Megacyllene (Megacyllene) insignita; Monné 2005: 90 (cat.).

Tegumento castanho-escuro. Protórax arredondado nos lados; pronoto com três faixas transversais de pubescência amarelada (em alguns exemplares a segunda faixa apenas vestigial). Élitros com quatro faixas transversais de pubescência amarelada (frequentemente a segunda esbranquiçada). Os quatro urosternitos basais com mancha lateral de pubescência amarela, as manchas do quarto ventrito frequentemente de pubescência esbranquiçada.

Comentários. Di Iorio (2006a: 7), ao sinonimizar $M$. insignita com M. latreillei não indicou os caracteres utilizados para justificar a sinonimia. Perroud (1855), ao descrever Clytus insignitus, caracterizou o pronoto com três faixas transversais de pubescência, diferindo de $M$. latreillei que só possui uma. Porém ao examinar alguns exemplares, foram encontrados indivíduos de $M$. insignita que apresentavam a segunda faixa apenas vestigial. Contudo outros caracteres permitem diferenciar $M$. insignita de $M$. latreillei como a presença das outras duas faixas anteriores de pubescência amarelada no pronoto em $M$. insignita, a posição da mancha sutural da quarta faixa, a qual se situa anteriormente do nível da faixa, e ao mesmo nível em $M$. latreillei e o padrão de manchas nas laterais dos ventritos, que em $M$. insignita ocorrem, frequentemente, nos quatro primeiros, enquanto que em $M$. latreillei ocorrem apenas nos três primeiros, sendo que, em ambos os casos a mancha distal é de coloração esbranquiçada.

Distribuição geográfica: Brasil (Rio Grande do Sul), Argentina (Córdoba, San Luis, Santa Fé, Corrientes, Entre Rios, Buenos Aires) e Uruguai. Amplia-se a distribuição no Brasil para Minas Gerais, Paraná e Santa Catarina.

Material examinado. BRASIL, Minas Gerais: Poços de Caldas (Morro do Futuro), macho, IV.1972, O Roppa e J. Becker col. Paraná: Curitiba, fêmea, I.1942, Moure col. Santa Catarina: Mafra, 2 fêmeas, XII.1938, A. Maller col. Rio Grande do Sul: fêmea. URUGUAI, Lavalleja: Mina Valencia, 2 fêmeas, 8.IV.1982, C.S. Carbonell col. Maldonado: Cerro Lemos, 2 fêmeas, 7.XII.1960, M. A. Monné col. Cerro Largo: Sierra de Aceguá, fêmea, 20.XI.1959, P.R San Martin col. Colônia: Playa Arenisca, fêmea, 57.XII.1970, M. S. Moratorio, R. Carballo \& G. J. Wibmer col. ARGENTINA, Buenos Aires: fêmea, XI.1953, H. Zellibor col. Córdoba: fêmea, 6.II.1940, Bridarolli col. (MNRJ); Anisacate, macho, H. H. Maristas col. (MNRJ); Entre Ríos: fêmea, I.1988, Liebig col. (MNRJ); Pronunciamiento, fêmea, XII.1964. (MNRJ); Tucumán: macho, I.1937. Santa Fé: Vera, macho, 5-17.III.1920, Hayward \& Willink col. Todos no MNRJ.

\section{Megacyllene (Megacyllene) spixi (Laporte \& Gory, 1836)}

(Fig. 19)

Clytus spixi Laporte \& Gory, 1836: 92, pr. 17, fig. 107.

Megacyllene (Megacyllene) spixi; Monné 2005: 93 (cat.); Di Iorio 2006a: 11 (distr.).
Tegumento castanho-amarelado. Protórax arredondado nos lados; pronoto com três faixas transversais de pubescência amarelada. Élitros com três faixas transversais de pubescência amarelada, a basal descendente em curva da sutura para a margem, as outras duas transversais alargadas na sutura. Os quatro urosternitos basais com manchas laterais de pubescência amarela.

Distribuição geográfica: Brasil (Goiás e Rio Grande do Sul), Argentina (Catamarca, Córdoba, Corrientes, Entre Rios, Buenos Aires), Paraguai e Uruguai. Amplia-se a distribuição no Brasil para São Paulo e Paraná.

Material examinado. BRASIL, São Paulo: fêmea. Paraná: Laranjeiras do Sul, macho, I.1962, S. Sakagami col. URUGUAI, Artigas: fêmea, 20.II.1954, C. S. Carbonell col. Rivera: Cuñapirú (Cerro Miriñaque), 3 machos, fêmea, 28.II.1969, C. S. Carbonell, M. A. Monné \& P.R. San Martín col. ARGENTINA, Misiones: 2 fêmeas, X.1935. Buenos Aires: 4 machos, II.1952, H. Zellibor col.; Tandil, 250m, macho, fềmea, II.1956. Todos no MNRJ.

\section{Megacyllene (Megacyllene) castanea (Laporte \& Gory, 1836)}

(Fig. 20)

Clytus castaneus Laporte \& Gory, 1836: 10, pr. 3, fig. 10.

Megacyllene (Megacyllene) castanea; Monné 2005: 88 (cat.); Di Iorio 2006a: 4 (distr.).

Tegumento castanho-amarelado. Protórax arredondado nos lados, levemente escavado na base; pronoto e élitros cobertos por curta e densa pubescência acastanhada que oculta parcialmente as faixas e manchas; pronoto com três faixas transversais de pubescência amarelada. Élitros com cinco faixas transversais de pubescência amarelada. Os três ou quatro urosternitos basais com manchas laterais de pubescência amarela.

Distribuição geográfica: Brasil (Rio Grande do Sul), Argentina (Misiones a Buenos Aires) e Paraguai. Amplia-se a distribuição no Brasil para São Paulo e Santa Catarina.

Material examinado. BRASIL, São Paulo: Campinas, fêmea, 2.IX.1961, Parker col. São José Barreiro (Serra da Bocaina, 1680m), 2 fêmeas, II.1973, P. S. Motta col. Santa Catarina: Seara (Nova Teutonia), macho, fêmea, 17.X.1939, H. Zellibor col., fêmea, 17.XI.1952; F. Plaumann col., mesma localidade e coletor, fêmea, XI.1956, macho, 25.I.1957, fêmea, XI.1965, macho, 14.XI.1967, fêmea, 29.XI.1967. Rio Grande do Sul: Santo Augusto, 3 machos, 2 fêmeas, X.1966, O. Roppa col. Todos no MNRJ.

\section{Megacyllene (Megacyllene) proxima (Laporte \& Gory, 1836)}

(Fig. 21)

Clytus proximus Laporte \& Gory, 1836: 5, pr. 2, fig. 2.

Megacyllene (Megacyllene) proxima; Monné 2005: 92 (cat.); Di Iorio 2006a: 11 (distr.); Monné et al. 2009: 6 (distr); Monné et al. 2010: 239 (distr.). Cyllene elongata Chevrolat, 1861: 379.

Tegumento preto. Protórax lateralmente subanguloso no inicio do terço posterior; pronoto com três faixas transver- 
sais de pubescência amarelada. Élitros com cinco faixas transversais de pubescência amarelada, sendo a segunda a partir da base dividida em manchas. Os três urosternitos basais com manchas laterais de pubescência amarela.

Distribuição geográfica: Venezuela, Colômbia, Equador, Brasil (largamente distribuida), Paraguai, Argentina (Salta a Misiones) e Bolívia (Santa Cruz).

Material examinado. BRASIL, Minas Gerais: Maria da Fé, macho, XI.1980, G S. Andrade col. Poços de Caldas, macho, XII.1976, M. A. Monné col. Espirito Santo: Linhares, macho, XII.1964, B. Silva col., macho, XI.1971, B. Silva col. Rio de Janeiro: Parque Nacional do Itatiaia (700m), fêmea, 26.X.1964, P. R. San Martín e M. A. Monné col. Teresópolis, macho, 19.XI.1958, D. Zajciw col. São Paulo: São José Barreiro (Serra da Bocaina), 2 machos, XI.1969, P. S. Motta col. Paraná: Curitiba, 2 machos, fêmea,
IV.1941, H. Rodr. col. Santa Catarina: Corupa, macho, XI.1960; Mafra, macho, XII.1937, A. Maller col. Rio Grande do Sul: Aratinga, 2 fêmeas, 1527.II.1964, C. S. Carbonell, A. Mesa e M. A. Monné col. Todos no MNRJ.

\section{Megacyllene (Megacyllene) minuta}

\section{(Chevrolat, 1862)}

(Fig. 22)

Cyllene minuta Chevrolat, 1862a: 62.

Megacyllene (Megacyllene) minuta; Monné 2005: 91 (cat.).

Tegumento castanho-escuro. Protórax arredondado nos lados; pronoto com três faixas transversais de pubescência amarelada. Élitros com cinco faixas transversais de pubes-

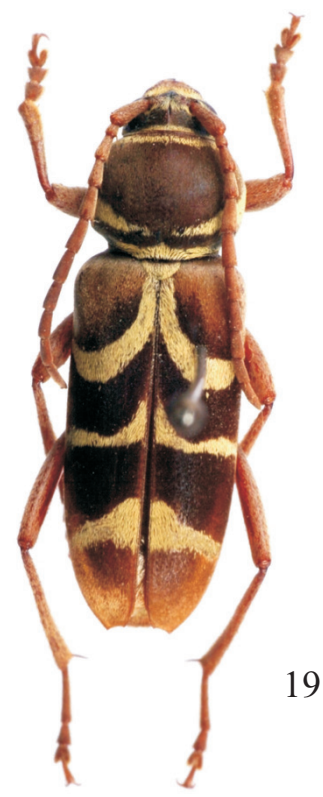

19
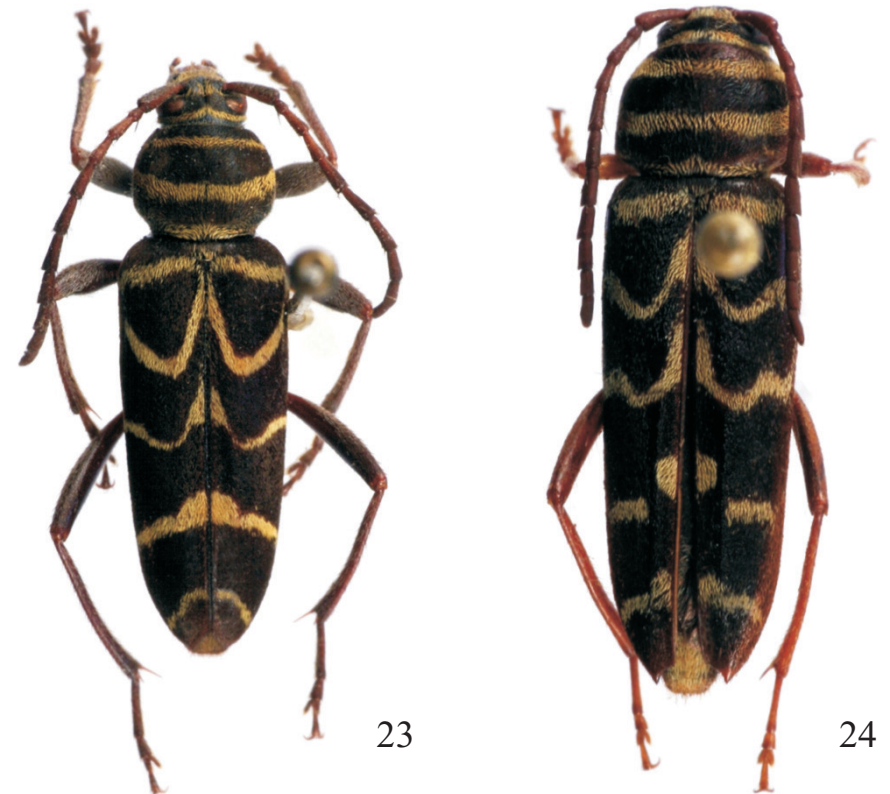

24

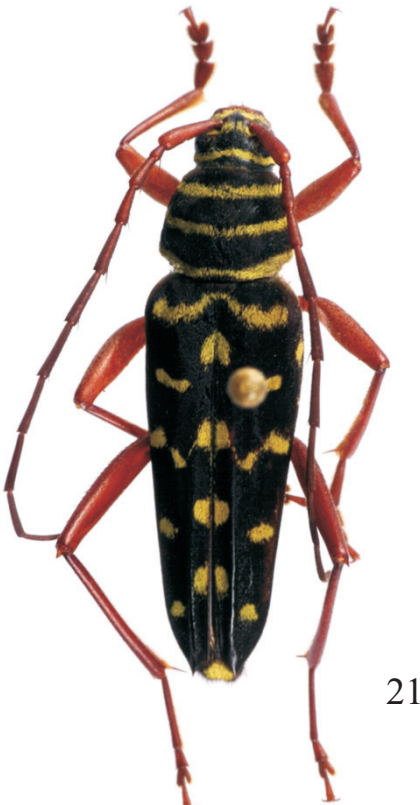

21

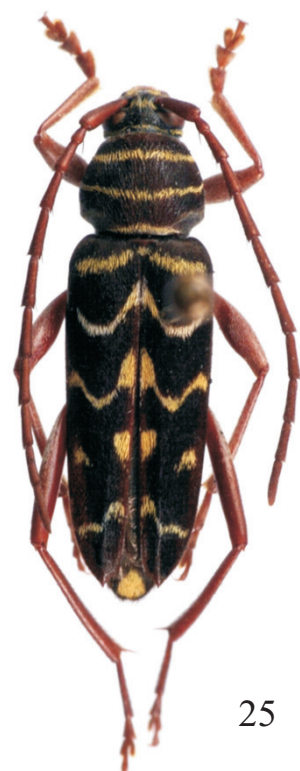

Figs. 19-25. 19, Megacyllene (Megacyllene) spixi; 20, M. (M.) castanea; 21, M. (M.) proxima; 22, M. (M.) minuta; 23, M. (M.) patruelis; 24. M. (M.) congener; 25, $M$. (M.) rufipes. 
cência amarelada. Os três ou quatro primeiros urosternitos com manchas laterais de pubescência amarela.

Comentários. Espécie de pequenas dimensões, no máximo 10,0 mm de comprimento total.

Distribuição geográfica: Brasil (Rio Grande do Sul), Argentina (Buenos Aires) e Uruguai. Amplia-se a distribuição no Brasil para Minas Gerais, Rio de Janeiro e Santa Catarina.

Material examinado. BRASIL, Rio de Janeiro: Duque de Caxias, fêmea, XI.1953, P. A. Telles col. Santa Catarina: Corupá, fêmea, I.1954, A. Maller col.; Mafra, macho, XII.1938, A. Maller col., fêmea, XII.1941, A. Maller col. Rio Grande do Sul: Pareci Novo, fêmea, 15.X.1930; Pelotas, fêmea, 27.X.1949, C. Biezanko col.; Porto Alegre, macho, 25.XI.1959, P. Buck col. URUGUAI, Artigas: 3 machos, 10.XII.1966, C. S. Carbonell, M. A. Monné \& P. R. San Martín col. Lavalleja: macho, fêmea, 14.XII.1987, C.S. Carbonell col.ARGENTINA, Buenos Aires: Buenos Aires, 2 fêmeas, 3.XI.1040, J. Bosq. col., fêmea, 20.XI.1949, Bregante col. Todos no MNRJ.

\section{Megacyllene (Megacyllene) patruelis (Chevrolat, 1862)}

(Fig. 23)

Cyllene patruelis Chevrolat, 1862a: 53.

Megacyllene (Megacyllene) patruelis; Monné 2005: 92 (cat.); Monné et al. 2009: 6, fig. 11 (distr); Monné et al. $2010: 239$ (distr.).

Tegumento preto; protórax arredondado nos lados, levemente escavado na base; pronoto com três faixas transversais de pubescência amarelada. Élitros com cinco faixas transversais de pubescência amarelada. Os três urosternitos anteriores com manchas laterais de pubescência amarela.

Distribuição geográfica: Brasil (Rio de Janeiro) e Uruguai. Amplia-se a distribuição no Brasil para São Paulo.

Material examinado. BRASIL, Rio de Janeiro: Itatiaia, 1 macho, 19.II.1932. São Paulo: Campos do Jordão, 2 machos, 6-8.II.1956, Ebenezer col.; São José Barreiro (Serra da Bocaina, 1680m), 2 machos, 2 fêmeas, II.1973, P. S. Motta col. mesma localidade, (1650m), fêmea, XI.1969, Seabra \& Oliveira col. Todos no MNRJ.

\section{Megacyllene (Megacyllene) congener (Laporte \& Gory, 1836)}

(Fig. 24)

Clytus congener Laporte \& Gory, 1836: 8, pr. 3, fig. 7

Megacyllene (Megacyllene) congener; Monné 2005: 89 (cat.); Monné et al. 2009: 6 (distr); Monné et al. 2010: 239 (distr.).

Tegumento preto. Protórax subanguloso no início do terço posterior; pronoto com três faixas transversais de pubescência amarelada. Élitros com cinco faixas transversais de pubescência amarelada, a primeira reta e as posteriores arqueadas. Os quatro primeiros urosternitos com manchas laterais de pubescência amarela.

Distribuição geográfica: Brasil (Minas Gerais, Rio de Janeiro). Amplia-se a distribuição para São Paulo, Santa Catarina e Rio Grande do Sul.
Material examinado. BRASIL, São Paulo: São José Barreiro (Serra da Bocaina, 1680m), fêmea, Seabra \& Oliveira col.; macho, 2 fềmeas, II.1972, P. S. Motta col.; mesma localidade e coletor, macho, 3 fêmeas, II.1973. Rio de Janeiro: Rio de Janeiro (Corcovado), fềmea, 27.X.1952, D. Zajciw col. (MNRJ); mesma localidade e coletor, macho, 14.XI.1952; macho, 15.X.1954; mesma localidade, macho, 14.I.1963, Alvarenga \& Seabra col.; fêmea, 21.II.1970, C. Beduin col.; Itatiaia, macho, 1-9.II.1957, A. Martínez \& M. V. D’Andretta col. Santa Catarina: Corupá, macho, III.1938, A. Maller col.; fêmea, XI.1949, A. Maller col.; São Bento do Sul, fêmea, XI.1937, A. Maller col. Rio Grande do Sul: Santo Augusto, 2 machos, X.1966, O. Roppa col. Todos no MNRJ.

\section{Megacyllene (Megacyllene) rufipes (Laporte \& Gory, 1836)}

(Fig. 25)

Clytus rufipes Laporte \& Gory, 1836: 8, pr. 2, fig. 6.

Megacyllene (Megacyllene) rufipes; Monné 2005: 93 (cat.); Monné et al. 2009: 6 (distr); Monné et al. 2010: 239 (distr.).

Tegumento preto. Protórax subanguloso no início do terço posterior; pronoto com três faixas transversais de pubescência amarelada. Élitros com cinco faixas transversais de pubescência amarelada, às vezes a segunda esbranquiçada. Os três ou quatro urosternitos basais com manchas laterais de pubescência amarela.

Distribuição geográfica: Brasil (Rio de Janeiro ao Rio Grande do Sul), Argentina (Misiones, Corrientes) e Uruguai.

Material examinado. BRASIL, Rio de Janeiro: Rio de Janeiro (Corcovado), macho, 20.X.1952, D. Zajciw col.; (Floresta da Tijuca), macho, 2.II.1961, C A. Campos Seabra col. São Paulo: São José Barreiro (Serra da Bocaina, 1600m), macho, 4 fêmeas, XI.1965, Alvarenga e Seabra col. Paraná: Guairá, 2 machos, 2 fêmeas, 27.IX.1986, M. A. Monné col. Santa Catarina: Mafra, fêmea, XII.1937, A. Maller col.; Pinhal, macho, XII.1949, A. Maller col. Rio Grande do Sul: Santo Augusto, macho, IV.1966, O. Roppa col.; macho, X.1966, O. Roppa col. Todos no MNRJ.

\section{AGRADECIMENTOS}

À Dilma Solange Napp (DZUP) e Orlando Tobias (MPEG) pelo empréstimo de material. Ao CNPq pela bolsa de Apoio Técnico do primeiro autor (Proc. 501261/2008-7), graduando do Curso de Ciências Biológicas da Universidade Federal do Rio de Janeiro.

\section{REFERÊNCIAS}

Aurivillius, C. 1913. Neue oder wenig bekannte Coleoptera Longicornia. 13. Arkiv för Zoologi 8: 229-263.

Casey, T. L. 1912. Studies on the Longicornia of North America. Memoirs on the Coleoptera 3: 215-376.

Chevrolat, L. A. 1860. Description d'espèces de Clytus propres au Mexique. Annales de la Société Entomologique de France 8: 451-504.

Chevrolat, L. A. 1861. Description de clytides de l'ancienne Colombie. Annales de la Société Entomologique de France 1: 377-388.

Chevrolat, L. A. 1862a. Description des clytides du Brésil. Annales de la Société Entomologique de France 2: 49-67.

Chevrolat, L. A. 1862b. Description de clytides américains. Annales de la Société Entomologique de France 2: 517-536.

Di Iorio, O. 1995. The genus Neoclytus Thomson, 1860 (Coleoptera, Cerambycidae, Clytini) in Argentina. Insecta Mundi 9: 335-346. 
Di Iorio, O. 2006a. New records, synonymies and a new Clytini from South America (Coleoptera, Cerambycidae, Cerambycinae). Les Cahiers Magellanes 58: 1-28.

Di Iorio, O. 2006b. New records, remarks and corrections to host plants of Cerambycidae (Coleoptera) from Argentina. Giornale Italiano di Entomologia 11: 159-178.

Fisher, W. S. 1945. A change of name in Cerambycidae. Proceedings of the Entomological Society of Washington 47: 251.

Fuchs, E. 1955. 1. Beitrag zur Kenntnis der neotropischen Cerambyciden. Koleopterologische Rundschau 33: 47-53.

Fuchs, E. 1961. Zwei neue Cyllene-Arten aus der Sammlung des Senckenberg-Museums. Senckenbergiana Biologica 42: 447-450.

Galileo, M. H. M. \& U. R. Martins, 2006. Inventário descritivo, p. 65-309. In: Cerambycidae (Coleoptera, Insecta) do Parque Copesul de Proteção Ambiental, Triunfo, Rio Grande do Sul, Brasil. Porto Alegre, Museu de Ciências Naturais da Fundação Zoobotânica do Rio Grande do Sul, $316 \mathrm{p}$

Germar, E. F. 1821. Neue exotische Käfer beschrieben von C. R. W. Wiedemann u. E. F. Germar. Magazin der Entomologie 4: 107-183.

Gounelle, E. 1911. Liste des cérambycides de la région de Jatahy, Etat de Goyaz, Brésil. Annales de la Société Entomologique de France 80: $1-150$.

Laporte, F. L. N. \& H. L. Gory. 1836. Monographie du genre Clytus. In: Histoire Naturelle et iconographie des insectes coléoptères, publié par monographies séparées. Duménil, 3, 124 p.

Linsley, E. G. 1964. The Cerambycidae of North America. Part V. Taxonomy and classification of the subfamily Cerambycinae, tribes Callichromini through Ancylocerini. University of California Publications in Entomology 22: 1-197.
Melzer, J. 1931. Novos cerambicídeos neotrópicos. Revista de Entomologia 1: 191-199.

Monné, M. A. 2005. Catalogue of the Cerambycidae (Coleoptera) of the Neotropical Region. Part I. Subfamily Cerambycinae. Zootaxa 946: $1-765$.

Monné, M. L.; M. A. Monné \& J. R. M. Mermudes. 2009. Inventário das espécies de Cerambycinae (Insecta, Coleoptera, Cerambycidae) do Parque Nacional do Itatiaia, RJ, Brasil. Biota Neotropica 9: 1-30.

Monné, M. L.; M. A. Monné; R. S. Martins; M. V. P. Simões \& V. S. Machado.2010 (2009). Espécies de Cerambycidae (Insecta, Coleoptera) ocorrentes no Estado do Rio de Janeiro (Brasil). Arquivos do Museu Nacional 67: 235-251.

Monné, M. A. \& D. S. Napp. 2004. Megacyllene Casey (Coleoptera, Cerambycidae): novas sinonímias e descrição de uma nova espécie. Revista Brasileira de Entomologia 48: 323-324.

Newman, E. 1840. Entomological notes. The Entomologist 1: 1-16.

Perroud, B. P. 1855. Description de quelques espèces nouvelles ou peu connus et création de quelques nouveaux genres dans la famille des longicornes. Annales de la Société Linnéenne de Lyon 2: 327-401.

Tippmann, F. F. 1953. Studien über neotropische Longicornier I (Coleoptera: Cerambycidae). Dusenia 4: 181-228.

White, A. 1855. Catalogue of the coleopterous insects in the collection of the British Museum. Longicornia 2. British Museum, London 8 : $175-412$.

Zajciw, D. 1962. Estudos sobre longicórneos neotrópicos III (Coleoptera, Cerambycidae). Revista Brasileira de Biologia 22: 449-452.

Zajciw, D. 1963. Novos longicórneos neotrópicos da tribo Clytini (Col., Cerambycidae, Cerambycinae). Revista Brasileira de Biologia 23: 171-179.

Received 5/7/2010; accepted 19/4/2011

Editor: Lúcia Massutti de Almeida 